\title{
Complete atrioventricular nodal block after propofol administration in an elderly patient undergoing total knee replacement arthroplasty -A case report-
}

\author{
Jung-Il Noh ${ }^{1}$, Joon-Ho Lee ${ }^{1}$, Seung-Yeon Woo $^{2}$, Young-Kwon Kim , Sung-Hwan Cho ${ }^{1}$, Sang-Hyun Kim , \\ and Won-Seok Chae ${ }^{1}$
}

Department of Anesthesiology and Pain Medicine, ${ }^{1}$ Soonchunhyang University, Bucheon Hospital, Bucheon, ${ }^{2}$ Soonchunhyang University, Gumi Hospital, Gumi, Korea

Complete atrioventricular (AV) block is defined as a dissociation of atrial and ventricular activities. Complete AV block that occurs during the perioperative period is difficult to reverse and usually requires implantation of a pacemaker. Propofol does not affect a normal AV conduction system but may act as a trigger for AV block. It can also potentiate vagal stimulation factors and reduce sympathetic activity. We report a case of complete AV block that may have been related to administration of propofol. (Korean J Anesthesiol 2013; 64: 363-366)

Key Words: Arrhythmia, Atrioventricular block, Pacemaker, Propofol.

Complete atrioventricular (AV) block occurs when no electrical impulses are conducted from the upper to lower chambers of the heart [1]. It is associated with high mortality and sudden death, myocardial infarction, and progressive heart failure until a pacemaker is inserted. However, the prognosis of a complete AV block improves greatly once a pacemaker is inserted [2].

Propofol has been one of the most widely used drugs for anesthesia since the early 1980s. It has several advantages over other anesthetics, such as smooth induction and a good recovery profile [3]. However, various types of arrhythmias are associated with the infusion of propofol [4]. Propofol may prolong AV conduction (or stimulus-to-His bundle interval) and Wenckebach cycle length in a concentration-dependent manner [5]. It can also decrease heart rate via central sympatholytic or vagotonic mechanisms rather than depression of baroreceptors [6].

We present a patient who experienced complete AV block that persisted after propofol administration during the induction of anesthesia for total knee replacement arthroplasty (TKRA).

Received: March 7, 2012. Revised: 1st, April 25, 2012; 2nd, May 16, 2012. Accepted: July 13, 2012.

Corresponding author: Joon-Ho Lee, M.D., Ph.D., Department of Anesthesiology and Pain Medicine, Soonchunhyang University, Bucheon Hospital, 1174, Jung-dong, Wonmi-gu, Bucheon 420-767, Korea. Tel: 82-32-621-5340, Fax: 82-32-621-5322, E-mail: anpjuno@schmc.ac.kr 두 This is an open-access article distributed under the terms of the Creative Commons Attribution Non-Commercial License (http:// creativecommons.org/licenses/by-nc/3.0/), which permits unrestricted non-commercial use, distribution, and reproduction in any medium, provided the original work is properly cited. 


\section{Case Report}

An 80-year-old woman (weight, $53 \mathrm{~kg}$; height, $154 \mathrm{~cm}$ ) was scheduled for TKRA of the left knee due to degenerative joint disease. She was diagnosed with hypertension 1 year ago but did not receive any medication. Preoperative blood and coagulation tests were normal. She had not undergone any previous operations. At admission, her vital signs were stable. Preoperative electrocardiography (ECG) showed normal sinus rhythm and a complete right bundle branch block (Fig. 1). A chest X-ray showed a hypertensive heart contour. We did not perform an echocardiogram, because it was obtained at another hospital, and cardiac function was normal except for the hypertension.

The patient was premedicated with glycopyrrolate $0.2 \mathrm{mg}$ intramuscularly $30 \mathrm{~min}$ before anesthesia. Upon arrival in the operating room, standard ECG, pulse oximeter, noninvasive blood pressure, and bispectral index monitoring (Model A-2000; Aspect Medical Systems, Newton, MA, USA) were applied. Her vital signs were pulse rate, 76 beats/min (bpm); oxygen saturation, 97\%; and blood pressure, 177/83 $\mathrm{mmHg}$. Anesthesia was induced with $40 \mathrm{mg}$ lidocaine and $60 \mathrm{mg}$ propofol. Rocuronium was given at a dose of $0.6 \mathrm{mg} / \mathrm{kg}$ to facilitate endotracheal intubation after loss of consciousness. After a few minutes, the ECG showed a complete AV block and ventricular rhythm of about $40 \mathrm{bpm}$ (Fig. 2). Despite the administration of $0.5 \mathrm{mg}$ atropine, the arrhythmia persisted (blood pressure, 90/40 mmHg; pulse rate, $30-49 \mathrm{bpm}$ ). At that time, her trachea was intubated with a 7.0-sized endotracheal tube under direct laryngoscopy, and a radial arterial line was placed for continuous arterial pressure monitoring and blood gas analysis. A central venous catheter was also inserted via the right internal jugular vein catheter. About 10 minutes after the propofol injection, her blood pressure was 145/55 mmHg, and her pulse rate was $66 \mathrm{bpm}$. The ECG showed a sinus rhythm. The operation was delayed, and she was transferred to the intensive care unit until fully awake for close observation and further evaluation.

We assessed the patient's creatine kinase-MB, troponin $\mathrm{T}$,
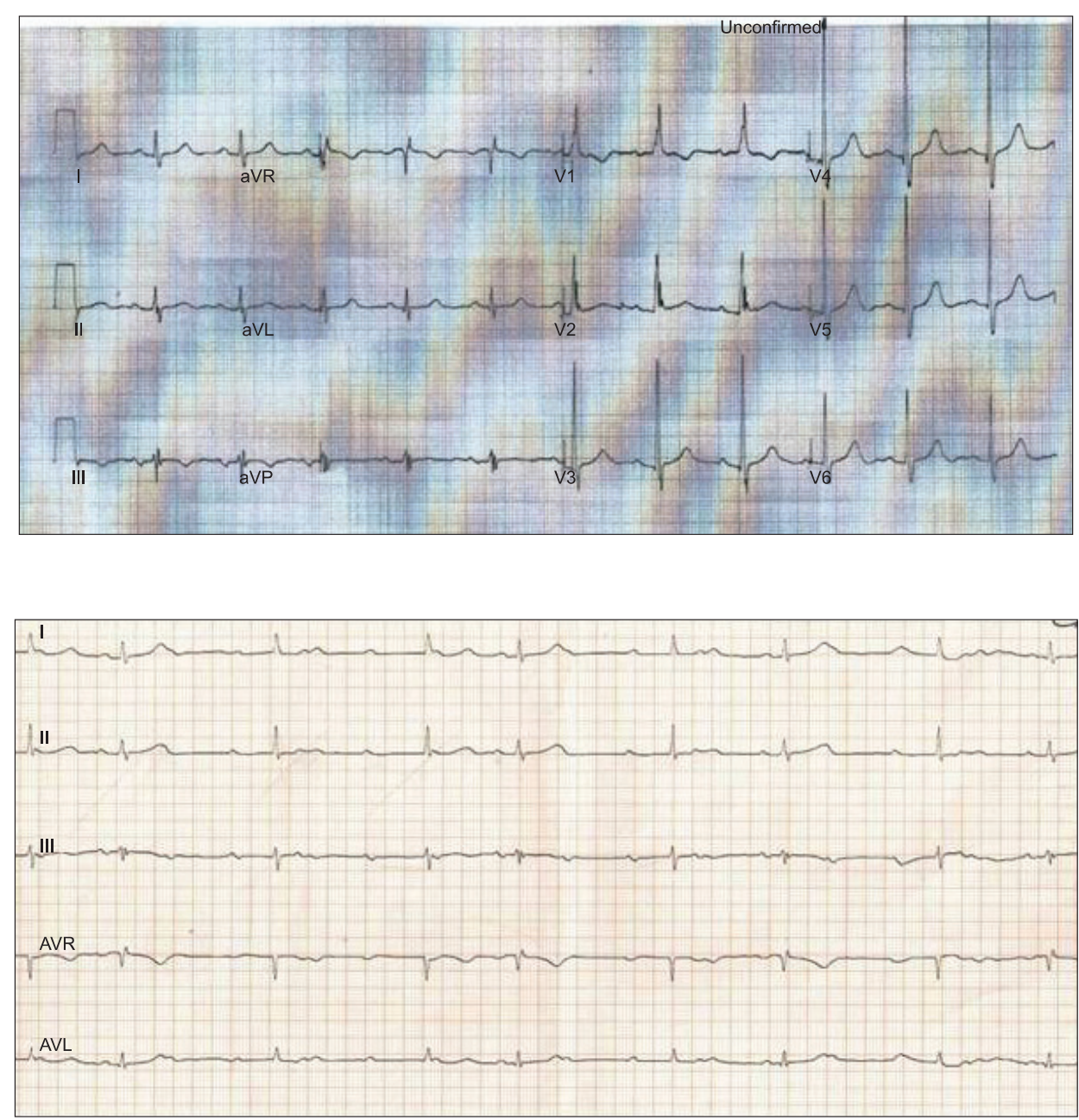

Fig. 1. Preoperative electrocardiogram.

Fig. 2. Complete atrioventricular block that occurred when propofol was injected. 


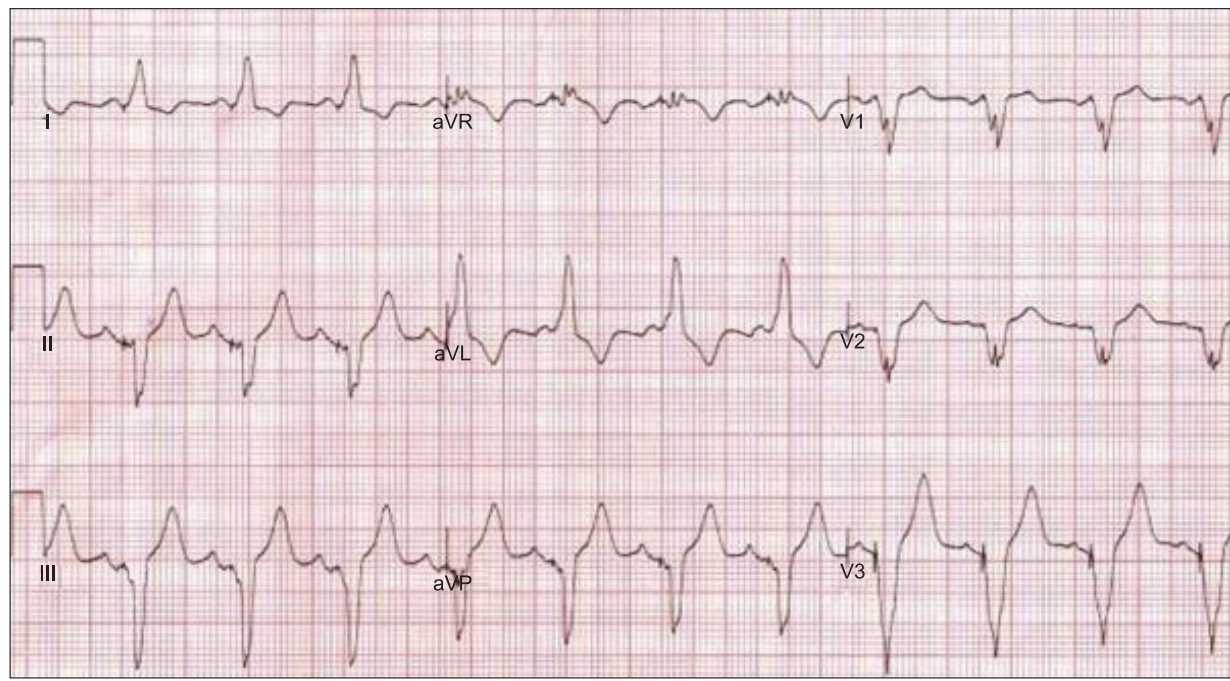

Fig. 3. Electrocardiogram taken after insertion of a permanent pacemaker. and myoglobin, and all values were normal. An echocardiography taken the next day exhibited a left ventricular ejection fraction of $63 \%$, which was suggestive of an indeterminate left ventricular filling pattern due to complete AV block. In addition, a 24-h ECG Holter monitor showed AV dissociation. Three-dimensional (3D) computed tomography of the heart revealed that the proximal and middle parts of the left anterior descending artery were narrowed by $50 \%$. She also had a focal aortic valve and mitral annular calcification.

We had planned to perform the surgery again. She received a temporary pace maker (VDD mode) with the minimum rate was set to $60 \mathrm{bpm}$. She was taken to the operating room, where her blood pressure was 180/95 $\mathrm{mmHg}$ and pulse rate was 72 bpm. A 22-gauge catheter was placed in the left radial artery for blood pressure monitoring. A central venous catheter was already inserted via the right internal jugular vein. The patient was placed in the right lateral decubitus position, and spinal anesthesia was performed at the L4/L5 interspinous space with $0.5 \%$ hyperbaric bupivacaine $8 \mathrm{mg}$. The sensory level reached the 10th thoracic segment. The surgeon then began the operation with an initial blood pressure of $170 / 80 \mathrm{mmHg}$ and a heart rate of $90 \mathrm{bpm}$. The operation lasted about $2 \mathrm{~h}$. She asked for sedation and we administered midazolam $3 \mathrm{mg}$ intravenously. However, because adequate sedation was not achieved, she received a continuous infusion ( $50 \mu \mathrm{g} / \mathrm{kg} / \mathrm{min})$. A few minutes after the propofol infusion, the ECG showed a complete AV block with a ventricular rhythm of about $40 \mathrm{bpm}$. The complete AV block disappeared soon after the propofol infusion was stopped. During the remainder of the surgery, her vital signs were stable. At the end of the operation, she had a blood pressure of 150/55 $\mathrm{mmHg}$, a pulse rate of $55 \mathrm{bpm}$, and oxygen saturation of $96 \%$.

A permanent pacemaker (DDDR mode) on postoperative day
2 was inserted (Fig. 3). On postoperative day 27, she remained hemodynamically stable and was discharged from the hospital uneventfully.

\section{Discussion}

Complete AV block may even lead to asystole [7]. Complete AV block is a complete dissociation of atrial and ventricular activities. The ventricular escape mechanism can occur anywhere from the AV node to the bundle-branch of the Purkinje system [2]. In general, the causes of complete AV block include myocardial infarction, iatrogenic injuries and drugs, such as quinidine, procainamide, flecainide, beta-blockers, amiodarone and calcium channel blockers $[7,8]$.

The risk factors of AV block are fibrosis and sclerosis of the conduction system, ischemic heart disease and intraventricular conduction disturbance. Our patient may have been at risk for a complete AV block because she had conduction disorder (right bundle branch block), had mild coronary artery stenosis, and had annular calcification. However, although 3D computed tomography of the heart revealed that the proximal and middle parts of the left anterior descending artery were narrowed by $50 \%$, clinical features did not indicate a diagnosis of myocardial infarction, and normal cardiac enzyme values were obtained. There was no confirmed evidence of ischemia by a cardiologist. We may hane been able to rule out complete AV block due to myocardial infarction.

AV block occurred twice immediately after propofol administration in our patient. During the first operation, lidocaine, rocuronium and anesthetic agents, such as propofol and desflurane may have been the cause of the complete AV block. However, during the second operation, as the heart rate was kept $>60 \mathrm{bpm}$, the failure of the temporary pacemaker was not 
noticed before the AV block occurred after the administration of propofol without lidocaine. Therefore, the administration of propofol alone may have induced the complete AV block.

Propofol can affect AV nodes through depressed sympathetic outflow, enhanced vagal tone, and altered baroreceptor sensitivity [5]. Studies have also described a direct inhibitory effect of propofol on myocardial contractility. Propofol acts directly on the calcium channel proteins to diminish voltagedependent L-type calcium channels and cardiac contractility [9]. The L-type calcium channel plays an important role in the plateau phase of the cardiac action potential as well as to pacemaker activity in nodal cells. The influx of calcium ion through voltage-dependent L-type calcium channel plays an essential role in cardiac excitability and in coupling excitation to contraction. This influx of calcium ion triggers the release of intracellular stores of calcium ion from the sarcoplasmic reticulum, and the ensuing intracellular calcium ion transient results in activation of the myofilaments [10]. Therefore, propofol retards AV nodal conduction by directly suppressing calcium channels. Several reports have been published about propofol-associated cardiac arrhythmias or adverse events $[11,12]$.

Propofol may also produce sinus bradycardia and complete AV block in adult patients [13]. Yorozu et al. [14] reported a retrospective examination showing factors that influence intraoperative bradycardia in adult patients. They revealed that the most prominent factor to affect heart rate was premedication with atropine. Other factors such as the use of muscle relaxants, endotracheal intubation, and neuraxial blockade were determined to affect heart rate only temporarily. Atropine significantly antagonized propofol-induced stimulus to a His bundle interval prolongation [5].

The cardiovascular effects of propofol are a negative chronotropic effect, a negative dromotropic effect, and a frequencydependent effect [5]. The negative chronotropic effect of propofol is concentration-dependent based on slowing of spontaneous atrial rate. The negative dromotropic effect of propofol is concentration-dependent prolongation of AV nodal conduction time. This effect is predominantly mediated by $\mathrm{M}_{2}$ muscarinic receptors. The frequency-dependent effect of propofol is greater at faster atrial pacing rate than at slower atrial pacing rates.

Wu et al. [15] reported propofol has been shown to retard the atrial rate and depress the $\mathrm{AV}$ nodal conduction at concentration ranging from 10 to $100 \mu \mathrm{M}$, and propofol at $100 \mu \mathrm{M}$ might also cause AV block. They thought that the negative dromotropic and chronotropic effects of propofol have been potential properties of this drug which may be manifested in patients with diseased hearts.
In conclusion, complete AV block may be induced by propofol administration. In patients with risk factors, physicians should closely monitor patients in whom an arrhythmia occurs when anesthesia is induced with propofol.

\section{References}

1. Johansson BW. Complete heart block. A clinical, hemodynamic and pharmacological study in patients with and without an artificial pacemaker. Acta Med Scand Suppl 1966; 451: 1-127.

2. Rosen KM, Dhingra RC, Loeb HS, Rahimtoola SH. Chronic heart block in adults. Clinical and electrophysiological observations. Arch Intern Med 1973; 131: 663-72.

3. Deegan RJ. Propofol: a review of the pharmacology and applications of an intravenous anesthetic agent. Am J Med Sci 1992; 304: 45-9.

4. Fudickar A, Bein B. Propofol infusion syndrome: update of clinical manifestation and pathophysiology. Minerva Anestesiol 2009; 75: 339-44.

5. Alphin RS, Martens JR, Dennis DM. Frequency-dependent effects of propofol on atrioventricular nodal conduction in guinea pig isolated heart. Mechanism and potential antidysrhythmic properties. Anesthesiology 1995; 83: 382-94.

6. Cullen PM, Turtle M, Prys-Roberts C, Way WL, Dye J. Effect of propofol anesthesia on baroreflex activity in humans. Anesth Analg 1987; 66: 1115-20.

7. Epstein AE, DiMarco JP, Ellenbogen KA, Estes NA 3rd, Freedman RA, Gettes LS, et al. ACC/AHA/HRS 2008 Guidelines for DeviceBased Therapy of Cardiac Rhythm Abnormalities: a report of the American College of Cardiology/American Heart Association Task Force on Practice Guidelines (Writing Committee to Revise the ACC/AHA/NASPE 2002 Guideline Update for Implantation of Cardiac Pacemakers and Antiarrhythmia Devices): developed in collaboration with the American Association for Thoracic Surgery and Society of Thoracic Surgeons. Circulation 2008; 117: e350-408.

8. Hillis WS, Whiting B. Antiarrhythmic drugs. Br Med J (Clin Res Ed) 1983; 286: 1332-6.

9. Zhou W, Fontenot HJ, Liu S, Kennedy RH. Modulation of cardiac calcium channels by propofol. Anesthesiology 1997; 86: 670-5.

10. Kamp TJ, Hell JW. Regulation of cardiac L-type calcium channels by protein kinase A and protein kinase C. Circ Res 2000; 87: 1095-102.

11. Rewari V, Kaul H. Sustained ventricular tachycardia in long QT syndrome: is propofol the culprit? Anesthesiology 2003; 99: 764.

12. Sakabe M, Fujiki A, Inoue H. Propofol induced marked prolongation of QT interval in a patient with acute myocardial infarction. Anesthesiology 2002; 97: 265-6.

13. Morozowich ST, Saslow SB. Progression of asymptomatic bifascicular block to complete heart block during upper gastrointestinal endoscopy with propofol sedation. Can J Anaesth 2009; 56: 83-4.

14. Yorozu T, Iijima T, Matsumoto M, Yeo X, Takagi T. Factors influencing intraoperative bradycardia in adult patients. J Anesth 2007; 21: 136-41.

15. Wu MH, Su MJ, Sun SS. Age-related propofol effects on electrophysiological properties of isolated hearts. Anesth Analg 1997; 84: 964-71. 